\title{
Coeficiente de digestibilidade verdadeira dos aminoácidos e valores de aminoácidos digestíveis do milho submetido a diferentes temperaturas de secagem e períodos de armazenamento
}

\author{
Débora Cristine de Oliveira Carvalho ${ }^{1}$, Luiz Fernando Teixeira Albino ${ }^{2}$, José Geraldo de \\ Vargas Junior ${ }^{3}$, Rodrigo Santana Toledo ${ }^{1}$, Jean Eduardo de Oliveira ${ }^{1}$, Renata Mara de Souza ${ }^{1}$ \\ ${ }^{1}$ Pós-graduação em Zootecnia, DZO, UFV, Viçosa - MG \\ ${ }^{2}$ Departamento de Zootecnia da UFV, Viçosa - MG \\ ${ }^{3}$ Departamento de Zootecnia da UFES, Alegre - ES.
}

RESUMO - Determinou-se o coeficiente de digestibilidade verdadeira dos aminoácidos de amostras de milho submetidas a diferentes temperaturas de secagem (temperatura ambiente e secagem artificial a 80, 100 e $120^{\circ} \mathrm{C}$ ) e períodos de armazenamento (0, 60, 120 e 180 dias). A digestibilidade verdadeira dos aminoácidos foi determinada pelo método de “alimentação forçada” utilizando-se galos Leghorn adultos cecectomizados, alojados individualmente em baterias metálicas. Utilizou-se delineamento inteiramente casualizado em esquema fatorial $4 \times 4$ (quatro temperaturas de secagem e quatro períodos de armazenamento) com um galo por unidade experimental e oito repetições por temperatura de secagem e período de armazenamento. As perdas endógenas foram determinadas com galos em jejum. O aumento da temperatura de secagem ocasionou redução linear da digestibilidade de metionina + cistina e isoleucina e efeito quadrático sobre a digestibilidade de metionina, treonina, lisina, triptofano e fenilalanina. Os maiores coeficientes de digestibilidade de metionina, treonina, lisina, triptofano e fenilalanina foram observados nas temperaturas 40, 25, 27,32 e $40^{\circ} \mathrm{C}$, respectivamente, obtidas por equação de regressão. Observou-se redução linear da digestibilidade de metionina e treonina com o tempo de armazenamento. A temperatura de secagem e o tempo de armazenamento dos grãos de milho reduzem a digestibilidade da maioria dos aminoácidos.

Palavras-chave: galos cecectomizados, processamento, secagem artificial, tempo de armazenamento

\section{True digestibility of amino acids and digestible amino acids values of corn samples submitted to different drying temperatures and storage periods}

\begin{abstract}
The objective of this experiment was to determine the true digestibility (TD) of amino acids from corn samples submitted to different drying temperatures (room temperature and artificial drying at 80,100 and $120^{\circ} \mathrm{C}$ ), and different storage periods $(0,60,120$ and 180 days). The TD of amino acids was determined by the forced feeding method using cecectomized adult Leghorn roosters, placed in individual cages. A $4 \times 4$ factorial arrangement was used (four drying temperatures and four storage periods), in a completely randomized design, with eight replicates. The endogenous amino acids losses were determined with roosters in fasting. A linear reduction occurred for the methionine + cystine digestibility and a quadratic effect was found for methionine, threonine, lysine, tryptophan and phenylalanine, with the increasing of the drying temperature. Higher TD values for methionine, threonine, lysine, tryptophan and phenylalanine were observed at temperature $40,25,27,32$ and $40^{\circ} \mathrm{C}$, respectively, obtained by regression equation. A linear reduction occurred for the methionine and threonine digestibility with the storage periods. It could be conclusion that the drying temperature and storage periods of corn grains reduce the digestibility of most amino acids.
\end{abstract}

Key Words: artificial drying, cecectomized roosters, processing, storage period

\section{Introdução}

Nas formulações de rações eficientes e econômicas para a produção de carne e de ovos, o conhecimento exato do conteúdo total de aminoácidos dos ingredientes e de sua digestibilidade é de suma importância, principalmente porque as alterações desses valores são grandes, tanto entre alimentos como entre amostras do mesmo alimento submetido a diferentes tipos de processamento.

O balanceamento dos aminoácidos na ração deve ser o mais correto possível para que não ocorra excesso nem deficiência de qualquer aminoácido, de forma que 
todos sejam completamente aproveitados. O desbalanço pode provocar problemas na absorção e no aproveitamento dos aminoácidos, causando prejuízos no desempenho de aves e na exploração avícola, aumentando os custos (Coon, 1991).

O milho, apesar de ser uma fonte energética nas formulações de ração, contribui com aproximadamente $22 \%$ da proteína total em rações para frangos, assim, o conhecimento da digestibilidade dos aminoácidos do milho e de possíveis alterações no seu valor nutritivo é de grande importância.

As alterações de qualidade das matérias-primas são alguns dos principais problemas na indústria de alimentação animal, pois pode afetar a qualidade das rações e comprometer o desempenho dos animais. A umidade e a temperatura são os principais fatores responsáveis pelo desenvolvimento de fungos em grãos e contribuem para o aumento das perdas na qualidade dos grãos. Por isso, é necessário um programa de controle dessas perdas, com colheita no tempo certo e secagem dos grãos e armazenamento na forma correta e padronizada. A secagem e o armazenamento dos grãos devem ser realizados com temperatura e tempo adequados para evitar a desnaturação excessiva das proteínas e o comprometimento da digestibilidade dos aminoácidos.

Superaquecimento pode prejudicar a disponibilidade de nutrientes, como os aminoácidos. A lisina e a cistina são os aminoácidos mais afetados pelo aquecimento excessivo do alimento (NRC, 1994). Desta forma, o conhecimento da digestibilidade dos aminoácidos do milho submetido a diversas situações permite melhorar a utilização dos alimentos e a formulação de rações mais precisas.

Diante do exposto, o objetivo neste trabalho foi determinar os coeficientes de digestibilidade verdadeira dos aminoácidos e os aminoácidos digestíveis de amostras de milho submetidas a secagem natural (temperatura ambiente) ou artificial (temperaturas de $80,100,120^{\circ} \mathrm{C}$ ) e a diferentes períodos de armazenamento (0, 60, 120 e 180 dias).

\section{Material e Métodos}

Esta pesquisa foi realizada em duas etapas. Na primeira, foram realizadas as secagens de sete cargas completas do secador KW-25, com cada uma das temperaturas do ar de secagem estabelecidas $\left(80,100\right.$ e $\left.120^{\circ} \mathrm{C}\right)$. Em seguida, os grãos de milho foram armazenados durante 180 dias em silos metálicos. Durante esse período de armazenamento, amostragens para avaliação da qualidade dos grãos foram realizadas aos $0,60,120$ e 180 dias. No recebimento do produto, uma quantidade de grãos foi retirada para secagem à sombra, em local ventilado, e posteriormente submetida às mesmas condições de armazenagem e avaliações das amostras submetidas à secagem artificial.

As amostras foram utilizadas para avaliação física dos grãos, que inclui análises de porcentagem de grãos quebrados, suscetibilidade dos grãos à quebra, perda de peso dos grãos, teor de umidade dos grãos, grau de infestação, análise de micotoxinas dos grãos e avaliação biológica. Esta avaliação física fez parte do trabalho realizado por Campos (2001), portanto, não será discutida, apenas citada para maior compreensão da segunda etapa. As secagens natural e artificial foram concluídas quando o teor de umidade do milho atingiu 13\% para evitar o desenvolvimento de fungos durante o armazenamento.

$\mathrm{Na}$ segunda etapa, foram realizados quatro ensaios biológicos que corresponderam aos períodos de armazenamento. Nesta etapa foram determinados os coeficientes de digestibilidade verdadeira dos aminoácidos e o conteúdo de aminoácidos digestíveis de amostras de milho submetidas a secagem natural (temperatura ambiente) e secagem artificial (a 80,100 ou $120^{\circ} \mathrm{C}$ ), todas com teor de umidade de $13 \%$ e armazenadas por 0, 60, 120 ou 180 dias. Utilizou-se a técnica de alimentação forçada descrita por Sibbald (1979) com galos Leghorn adultos cecectomizados pesando $2.300 \mathrm{~g} \pm 50 \mathrm{~g}$.

As cirurgias de cecectomia dos galos foram realizadas no Setor de Avicultura, conforme metodologia descrita por Pupa et al. (1998). A temperatura média registrada no interior da sala durante os quatro ensaios biológicos foi $20 \pm 1^{\circ} \mathrm{C}$.

$\mathrm{O}$ experimento foi realizado em delineamento inteiramente casualizado, em esquema fatorial $4 \times 4$ (quatro temperaturas de secagem e quatro períodos de armazenamento), com um galo por unidade experimental e oito repetições por tratamento, utilizando-se um tratamento com galos em jejum, um galo por tratamento e oito repetições, para as correções das perdas endógenas e metabólicas. Assim, foram utilizados 40 galos em cada fase experimental, alojados em gaiolas individuais de baterias metálicas e mantidos em adaptação durante cinco dias, recebendo alimentação em dois turnos de 1 hora, um pela manhã e o outro à tarde, com o objetivo da dilatação do papo.

O período experimental foi de 92 horas. Os galos foram mantidos em jejum por um período de 36 horas para esvaziamento dos tratos digestivos. Em seguida, foram forçados a consumir $30 \mathrm{~g}$ do alimento-teste, introduzidos no inglúvio, por meio de um funil - sonda colocada via esôfago. O alimento-teste foi fornecido ( $15 \mathrm{~g}$ ) pela manhã e pela tarde (15 g) para evitar que os galos regurgitassem o alimento fornecido. Simultaneamente, oito galos permaneceram em jejum. 
As bandejas sob o piso da gaiolas foram revestidas com plástico para evitar perdas do material e a coleta de excretas foi realizada duas vezes por dia (às 8 e 16 h), por um período de 56 horas, depois de iniciado o fornecimento dos alimentos. Foram realizadas duas coletas ao dia para evitar fermentação das excretas. Anteriormente a cada período de coleta, todos os galos foram submetidos a um serviço completo de toillete, em que foram retiradas as penas ao redor da cloaca, a fim de evitar contaminação das excretas.

As excretas foram coletadas e acondicionadas em freezer até o final do experimento, quando foram descongeladas, pesadas, homogeneizadas e secas em estufa de ventilação forçada a $54^{\circ} \mathrm{C}$, durante 72 horas, para a pré-secagem. Em seguida, as amostras foram moídas e submetidas a análises laboratoriais de matéria seca (MS) e de nitrogênio $(\mathrm{N})$, segundo metodologia descrita por Silva (1990), no Laboratório de Nutrição Animal da Universidade Federal de Viçosa.

As análises de aminoácidos dos alimentos e das excretas foram realizadas no Laboratório da Mogiana Alimentos S. A. (Guabi, São Paulo).

Uma vez conhecida a quantidade de aminoácidos ingeridos e excretados, bem como a fração endógena determinada com galos em jejum, foram determinados os coeficientes de digestibilidade verdadeira de cada aminoácido e o conteúdo de aminoácido digestível verdadeiro dos alimentos, utilizando-se a fórmula proposta por Rostagno \& Featherston (1977), descrita seguir:

\section{CDVaa $=\underline{\text { AAing. }-(\text { AAexc. }- \text { AAend. }) \times 100}$}

\section{AAing.}

em que: $\mathrm{CDV}$ aa = coeficiente de digestibilidade verdadeira dos aminoácidos; AAing. = aminoácido ingerido, em gramas;
AAexc. = aminoácido excretado em gramas; e AAend. = aminoácido endógeno, em gramas.

Os dados foram submetidos a análises de variância e metodologia da superfície resposta utilizando-se o programa SAEG - Sistemas para Análises Estatísticas e Genéticas, (UFV, 1999).

\section{Resultados e Discussão}

Os valores de alguns aminoácidos essenciais e não-essenciais observados nas amostras de milho (Tabelas 1 e 2) foram inferiores aos encontrados na literatura (Rostagno, 2000; Pupa, 1998; Fisher Jr. et al., 1998; Pupa, 1995).

A composição em aminoácidos das amostras de milho diferiu de acordo com as temperaturas de secagem e os tempos de armazenamento. De forma geral, os teores de aminoácidos essenciais e não-essenciais reduziram com o aumento da temperatura de secagem e com o tempo de armazenamento.

Observou-se efeito quadrático $(\mathrm{P}<0,05)$ da temperatura de secagem sobre a composição em metionina, metionina+ cistina, treonina e triptofano. O maior conteúdo de treonina no milho foi observado na temperatura de $72^{\circ} \mathrm{C}$, obtida por equação de regressão (Tabela 3). Esse resultado está de acordo com o relatado por Hathaway et al. (1952) de que o valor nutritivo da proteína do milho reduz quando este alimento é submetido a secagem em temperatura superior a $71^{\circ} \mathrm{C}$. Neste estudo, a temperatura de secagem teve efeito linear $(\mathrm{P}<0,05)$ sobre a composição de lisina.

O tempo de armazenamento, por sua vez, teve efeito linear $(\mathrm{P} \leq 0,05)$ sobre os teores de metionina, metionina+ cistina, treonina e triptofano.

Tabela 1 - Composição de proteína bruta e aminoácidos essenciais, em porcentagem da matéria seca, de amostras de milho submetidas a diferentes temperaturas de secagem e períodos de armazenamento

\begin{tabular}{|c|c|c|c|c|c|c|c|c|c|c|c|c|c|c|c|c|}
\hline & \multicolumn{4}{|c|}{ Não armazenado } & \multicolumn{4}{|c|}{ Armazenado por 60 dias } & \multicolumn{4}{|c|}{ Armazenado por 120 dias } & \multicolumn{4}{|c|}{ Armazenado por 180 dias } \\
\hline & $27^{\circ} \mathrm{C}$ & $80^{\circ} \mathrm{C}$ & $100^{\circ} \mathrm{C}$ & $120^{\circ} \mathrm{C}$ & $27^{\circ} \mathrm{C}$ & $80^{\circ} \mathrm{C}$ & $100^{\circ} \mathrm{C}$ & $120^{\circ} \mathrm{C}$ & $27^{\circ} \mathrm{C}$ & $80^{\circ} \mathrm{C}$ & $100^{\circ} \mathrm{C}$ & $120^{\circ} \mathrm{C}$ & $27^{\circ} \mathrm{C}$ & $80^{\circ} \mathrm{C}$ & $100^{\circ} \mathrm{C}$ & $120^{\circ} \mathrm{C}$ \\
\hline & 85,23 & 84,98 & 84,81 & 84,92 & 5,27 & 85,16 & 84,96 & 85,24 & 86,91 & 86,31 & 86,21 & 86,55 & 86,61 & 86,42 & 86,39 & 86,45 \\
\hline$\%$ & 10,22 & 9,85 & 10,39 & 10,03 & 10,04 & 9,91 & 9,98 & 9,96 & 10,07 & 9,82 & 9,98 & 9,75 & 9,68 & 9,45 & 9,91 & 9,97 \\
\hline rginil & & 0,4 & & & & & & & & & & & & & & 0,452 \\
\hline nina & 0,208 & 0,199 & 201 & & & 0,194 & 0,199 & & & 0,197 & 0,196 & & & 95 & 0,197 & 0,196 \\
\hline $\begin{array}{l}\text { Metionina + } \\
\text { cistina }\end{array}$ & 0,427 & 0,415 & 0,419 & 0,397 & 0,412 & 0,402 & 0,428 & 0,413 & 0,405 & 0,411 & 0,405 & & 0,412 & 0,396 & 0,408 & 0,404 \\
\hline Treonina & 0,350 & 0,341 & & & & & & & & & & & & & & 0,348 \\
\hline Trip & 0,082 & 0,079 & 084 & & & & 0,071 & & & & 0,081 & & & & 0,073 & 0,070 \\
\hline & 0,348 & 0,337 & 0,4 & 0,3 & & 0,3 & & & & & 0,4 & & & & & 0,363 \\
\hline
\end{tabular}


Tabela 2 - Composição em aminoácidos não-essenciais, em porcentagem da matéria seca, de amostras de milho submetidas a diferentes temperaturas de secagem e períodos de armazenamento

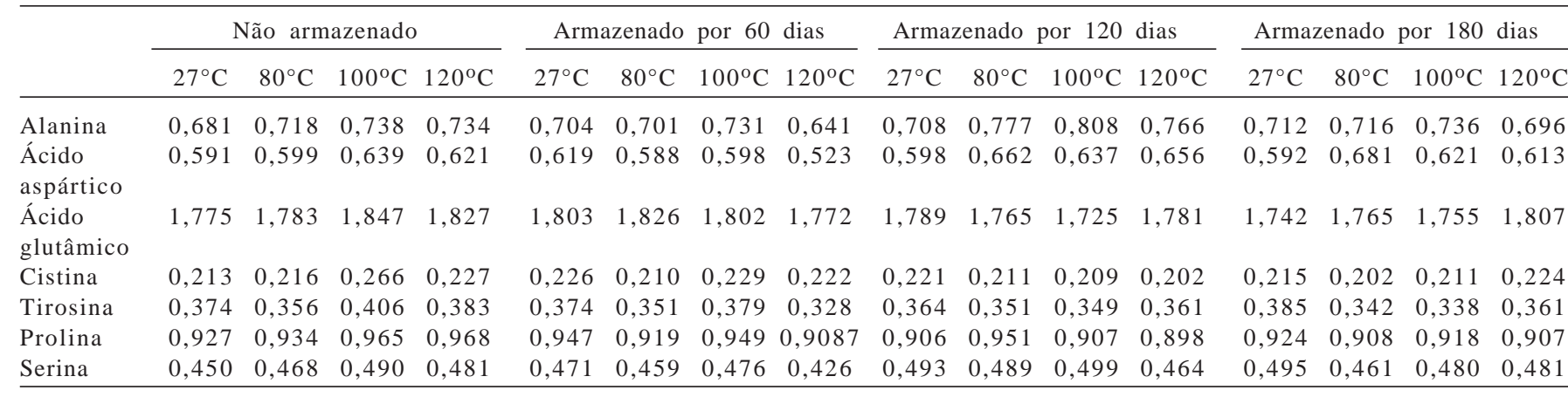

Tabela 3 - Equações de regressão ajustadas e coeficientes de determinação $\left(\mathrm{R}^{2}\right)$ dos aminoácidos totais de amostras de milho submetidas a diferentes temperaturas de secagem $(\mathrm{x})$ e períodos de armazenamento (z)

\begin{tabular}{lcc}
\hline Parâmetro & Equação de regressão & $\mathrm{R}^{2}$ \\
\hline Lisina & $\hat{\mathrm{Y}}=27,85-0,0003488^{*} \mathrm{x}$ & 0,85 \\
Metionina & $\hat{\mathrm{Y}}=19,74+0,0001299^{*} \mathrm{x}-0,0000014^{*} \mathrm{x}^{2}-0,0000070^{*} \mathrm{z}$ & 0,30 \\
Metionina + cistina & $\hat{\mathrm{Y}}=41,78+0,0000834^{*} \mathrm{x}-0,0000012^{*} \mathrm{x}^{2}-0,0000645^{*} \mathrm{z}$ & 0,32 \\
Treonina & $\hat{\mathrm{Y}}=33,49+0,0004063^{*} \mathrm{x}-0,0000028^{*} \mathrm{x}^{2}-0,0000188^{*} \mathrm{z}$ & 0,86 \\
Triptofano & $\hat{\mathrm{Y}}=0,083+0,0000357^{*} \mathrm{x}-0,0000008^{*} \mathrm{x}^{2}-0,0000220^{*} \mathrm{z}$ & 0,35 \\
\hline
\end{tabular}

* Significativo a $5 \%$ de probabilidade pelo teste t.

A redução na composição dos aminoácidos com o aumento de temperatura de secagem dos grãos era esperada, pois, segundo Araújo (1995), todos os aminoácidos, especialmente lisina, treonina e metionina, são sensíveis ao aquecimento. Essa redução do conteúdo de lisina foi semelhante à relatada por Hathaway et al. (1952).

Miller et al. (1965) observaram redução de $60 \%$ no conteúdo de cistina quando o alimento foi seco em temperatura acima de $100^{\circ} \mathrm{C}$. Segundo Moran et al. (1970), a cistina é sensível a alta temperatura, por isso, é destruída quando o alimento é submetido a superaquecimento. No entanto, neste estudo não foi observada alteração significativa no conteúdo de cistina do milho com a temperatura de secagem.

Os coeficientes de digestibilidade dos aminoácidos metionina + cistina e isoleucina reduziram de forma linear $(\mathrm{P}<0,05)$ com o aumento da temperatura de secagem. A temperatura de secagem teve efeito quadrático $(\mathrm{P}<0,05)$ sobre os coeficientes de digestibilidade dos aminoácidos metionina, treonina, lisina, triptofano e fenilalanina (Tabela 4). Os maiores valores dos coeficientes de digestibilidade verdadeira de metionina, treonina, lisina, triptofano e fenilalanina foram observados nas temperaturas $40,25,27,32$ e $40^{\circ} \mathrm{C}$, respectivamente, obtidas por equação de regressão (Tabela 5). Apenas os coeficientes de digestibilidade de metionina e de treonina foram alterados pelo tempo de armazenamento, que teve efeito linear $(\mathrm{P} \leq 0,05)$.

As proteínas, em sua maioria, são desnaturadas quando expostas a moderado aquecimento $\left(60\right.$ a $90^{\circ} \mathrm{C}$, por 1 hora ou menos). A desnaturação excessiva da proteína freqüentemente resulta na sua insolubilização, pois afeta suas propriedades funcionais e aumenta sua viscosidade. Do ponto de vista nutricional, a desnaturação parcial melhora a digestibilidade e a disponibilidade biológica de aminoácidos essenciais (Araújo, 1995). Assim, o efeito quadrático observado para os coeficientes de digestibilidade verdadeira de metionina, lisina, treonina, triptofano e fenilalanina pode ser atribuído à desnaturação das proteínas, que altera sua conformação original, permitindo que as proteases atuem mais facilmente, melhorando a digestibilidade. Conforme a temperatura de secagem aumentou, os coeficientes de digestibildade verdadeira desses aminoácidos reduziram, evidenciando dano na proteína e piora na digestibilidade, em decorrência do superaquecimento.

Em ratos alimentados com rações contendo milho superaquecido, Sullivan et al. (1973) observaram redução na solubilidade da proteína do milho com o aumento da temperatura de secagem do milho, que afetou negativamente o ganho de peso. Segundo esses autores, a temperatura de secagem afetou a utilização da proteína do milho pelo animal. 
Tabela 4 - Coeficientes de digestibilidade verdadeira dos aminoácidos do milho submetido a diferentes temperatura de secagem e tempos de armazenamento

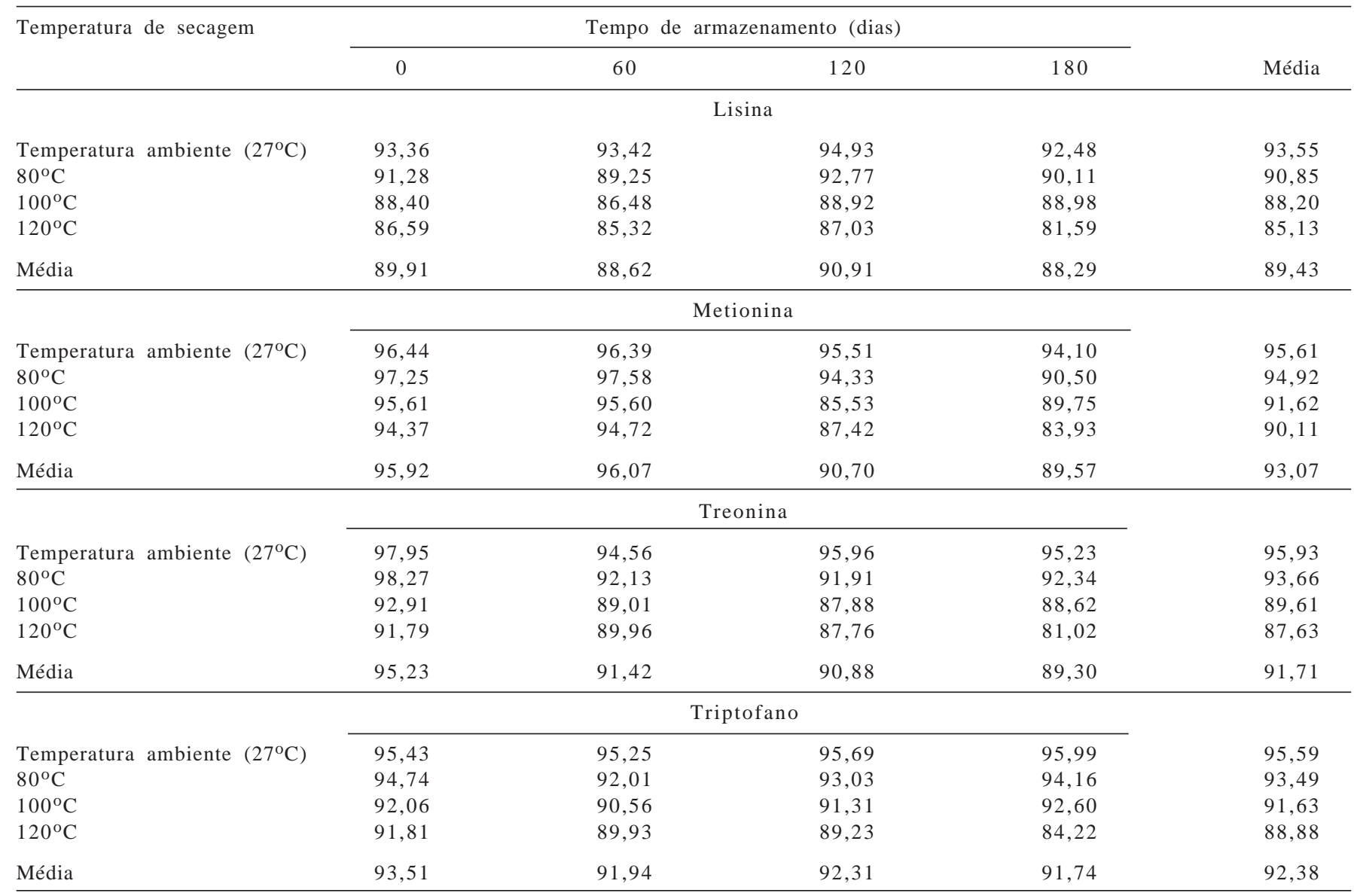

Tabela 5 - Equações de regressão ajustada e coeficiente de determinação $\left(\mathrm{R}^{2}\right)$ dos coeficientes de digestibilidade de aminoácidos de amostras de milho submetidas diferentes temperaturas de secagem (x) e tempos de armazenamento (z)

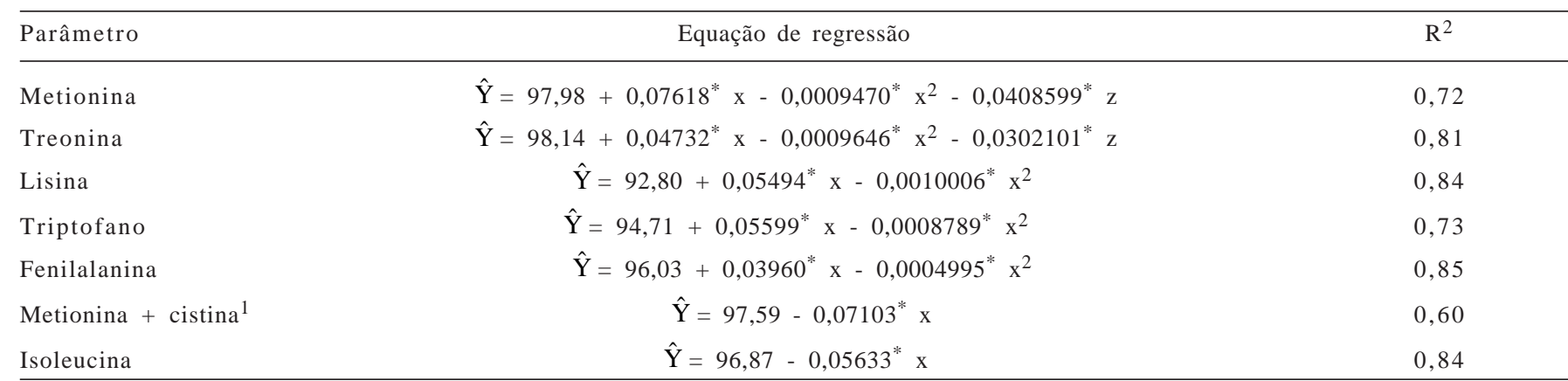

* Significativo a $5 \%$ de probabilidade pelo teste t.

O efeito negativo sobre a proteína, segundo Araújo (1995), ocorre durante a secagem com a utilização direta de ar quente. A perda de água imobilizada, especialmente da camada monomolecular, chamada água de superfície, provoca a desnaturação da proteína. A secagem artificial dos grãos de milho utilizado neste estudo foi realizada de forma rápida, o que provavelmente danificou a proteína. Segundo Justice \& Bass (1979), quando a evaporação ocorre rapidamente na superfície dos grãos de milho, o embrião pode ser danificado. O embrião é o componente do milho que possui maiores teores de lisina e triptofano (Sgarbieri, 1996).

Portanto, a diminuição da digestibilidade da proteína foi evidenciada pela redução nos coeficientes de digestibilidade dos aminoácidos com o aumento da temperatura de secagem. Além da desnaturação excessiva da proteína, outra explicação para a redução da digestibilidade desses aminoácidos é a ocorrência da reação de Maillard, 
um processo decorrente da interação entre lisina (possui grupo amino épsilon livre) ou arginina (possui átomo de nitrogênio básico na cadeia lateral) e um aldeído (açúcar redutor). A reação de Maillard, além de prejudicar a lisina ou arginina, afeta também a digestibilidade de outros aminoácidos (Tabelas 6 e 7), pois permite a formação de produtos que, provavelmente por efeitos estéricos (ligação tipo éster), são hidrolizados apenas parcialmente pelas enzimas proteolíticas, evitando o aproveitamento de parte dos aminoácidos dessa proteína pelo organismo animal.

Segundo Carpenter (1973), o organismo tem capacidade variável em absorver o complexo formado pela reação de Maillard. Alguns aminoácidos ligados a carboidratos podem ser absorvidos, mas o principal problema é a capacidade do animal em utilizar esses aminoácidos, pois muitas vezes são perdidos na urina e não têm valor nutricional para o animal. Costa et al. (1977), trabalhando com aves em crescimento alimentadas com rações contendo milho submetido a secagem artificial com temperaturas elevadas, e com dois teores de umidade (14 e 23\%), observaram redução de $11 \%$ na disponibilidade de lisina quando os grãos de milho tinham 23\% de umidade e foram secos em temperatura superior a $127^{\circ} \mathrm{C}$.

Com o aumento da temperatura de secagem, observou-se redução linear $(\mathrm{P}<0,05)$ dos níveis de lisina digestível e metionina + cistina digestível (Tabela 8). O tempo de

Tabela 6 - Valores médios de aminoácidos digestíveis essenciais, em porcentagem da matéria seca, de amostras de milho submetidas a diferentes temperaturas de secagem e tempos de armazenamento

\begin{tabular}{|c|c|c|c|c|c|c|c|c|c|c|c|c|c|c|c|c|}
\hline & \multicolumn{4}{|c|}{ Não armazenado } & \multicolumn{4}{|c|}{ Armazenado por 60 dias } & \multicolumn{4}{|c|}{ Armazenado por 120 dias } & \multicolumn{4}{|c|}{ Armazenado por 180 dias } \\
\hline & & & 449 & & & & & 0,413 & & & 451 & & & & 43 & 0,4 \\
\hline & 0,246 & 5 & & & & 6 & & & & & 0,213 & & & & 16 & 0,192 \\
\hline & 0,201 & 0,193 & 0,192 & & & 0,1 & & & & & 68 & & & & 177 & 0,165 \\
\hline $\begin{array}{l}\text { Ietionina + } \\
\text { istina }\end{array}$ & 0,416 & 0,400 & 0,392 & & 0,393 & 0,373 & 0,386 & & & & 0,344 & & & & 0,367 & 0,355 \\
\hline & 0,343 & 335 & & & & & & & 328 & 0,323 & 0,305 & & 24 & & 0,309 & 0,282 \\
\hline & 0,078 & & & & & & & & & & 0, & & & & & 0,059 \\
\hline & 0,312 & 0,292 & & & 332 & 0,305 & & & & & 0,345 & & & & & 0,300 \\
\hline Valina & 0,383 & 0,392 & 0,407 & 0,385 & 0,403 & 0,0385 & 0,385 & 0,371 & 0,391 & 0,377 & 0,377 & 0,370 & 0,397 & 0,399 & 0,405 & 0,385 \\
\hline
\end{tabular}

Tabela 7 - Valores médios de aminoácidos digestíveis não-essenciais, em porcentagem da matéria seca, de amostras de milho submetidas a diferentes temperaturas de secagem e períodos de armazenamento

\begin{tabular}{|c|c|c|c|c|c|c|c|c|c|c|c|c|c|c|c|c|}
\hline & \multicolumn{4}{|c|}{ Não armazenado } & \multicolumn{4}{|c|}{ Armazenado por 60 dias } & \multicolumn{4}{|c|}{ Armazenado por 120 dias } & \multicolumn{4}{|c|}{ Armazenado por 180 dias } \\
\hline & $27^{\circ} \mathrm{C}$ & $80^{\circ} \mathrm{C}$ & $100^{\circ} \mathrm{C}$ & $120^{\circ} \mathrm{C}$ & $27^{\circ} \mathrm{C}$ & $80^{\circ} \mathrm{C}$ & $100^{\circ} \mathrm{C}$ & $120^{\circ} \mathrm{C}$ & $27^{\circ} \mathrm{C}$ & $80^{\circ} \mathrm{C}$ & $100^{\circ} \mathrm{C}$ & $120^{\circ} \mathrm{C}$ & $27^{\circ} \mathrm{C}$ & $80^{\circ} \mathrm{C}$ & $100^{\circ} \mathrm{C}$ & $120^{\circ} \mathrm{C}$ \\
\hline Alanina & 0,651 & 0,669 & 0,669 & 0,681 & 0,679 & 0,677 & 0,693 & 0,603 & 0,661 & 0,707 & 0,689 & 0,416 & 0,675 & 0,666 & 0,689 & 0,647 \\
\hline $\begin{array}{l}\text { Ácido } \\
\text { glutâmico }\end{array}$ & 1,721 & 1,740 & 1,751 & 1,748 & 1,784 & 1,722 & 1,758 & 1,70 & 1,734 & 1,686 & 1,676 & 1,715 & 1,693 & 1,653 & 1,619 & 1,694 \\
\hline Prolina & 0,876 & 0,876 & 0,920 & 0,902 & 0,890 & 0,872 & 0,896 & 0,868 & 0,880 & 0,901 & 0,848 & 0,886 & 0,876 & 0,823 & 0,848 & 0,853 \\
\hline Serina & 0,447 & 0,0449 & 0,449 & 0,446 & 0,441 & 0,439 & 0,449 & 0,400 & 0,476 & 0,442 & 0,442 & 0,431 & 0,474 & 0,430 & 0,443 & 0,444 \\
\hline
\end{tabular}

Tabela 8 - Equações de regressão ajustada e coeficientes de determinação $\left(\mathrm{R}^{2}\right)$ dos aminoácidos digestíveis de amostras de milho submetidas a diferentes temperaturas de secagem $(\mathrm{x})$ e tempos de armazenamento $(\mathrm{z})$

\begin{tabular}{lccc}
\hline Parâmetro & Equação de regressão & $\mathrm{R}^{2}$ \\
\hline Metionina & $\hat{\mathrm{Y}}=0,1936+0,0002694^{*} \mathrm{x}-0,0000032^{*} \mathrm{x}^{2}-0,0000872^{*} \mathrm{z}$ & 0,80 \\
Treonina & $\hat{\mathrm{Y}}=0,3295+0,0005285^{*} \mathrm{x}-0,0000058^{*} \mathrm{x}^{2}-0,000123^{*} \mathrm{z}$ & 0,70 \\
Triptofano & $\hat{\mathrm{Y}}=0,0795+0,0000648^{*} \mathrm{x}-0,0000014^{*} \mathrm{x}^{2}-0,0000259^{*} \mathrm{z}$ & 0,54 \\
Fenilalanina & $\hat{\mathrm{Y}}=0,5144+0,0001679^{*} \mathrm{x}-0,0000029^{*} \mathrm{x}^{2}-0,0003515^{*} \mathrm{z}$ & 0,78 \\
Lisina & $\hat{\mathrm{Y}}=0,2677-0,0005359^{*} \mathrm{x}$ & 0,93 \\
Metionina + cistina & $\hat{\mathrm{Y}}=0,4074-0,0003756^{*} \mathrm{x}$ & 0,40 \\
\hline
\end{tabular}

* Significativo a $5 \%$ de probabilidade pelo teste $t$. 
armazenamento, no entanto, não alterou $(\mathrm{P}>0,05)$ a digestibilidade desses aminoácidos. A variação da temperatura de secagem teve efeito quadrático $(\mathrm{P}<0,05)$ sobre os níveis de metionina digestível, treonina digestível, triptofano digestível e fenilalanina digestível (Tabela 8). Com o aumento do tempo de armazenamento, observou-se redução linear $(\mathrm{P}<0,05)$ na digestibilidade desses aminoácidos.

\section{Conclusões}

O conteúdo da maioria dos aminoácidos essenciais e não-essenciais do milho foi reduzido quando os grãos de milho foram submetidos a elevada temperatura de secagem e por longo período de armazenamento. A temperatura de secagem dos grãos de milho reduziu a digestibilidade da maioria dos aminoácidos, principalmente metionina, lisina, metionina + cistina, treonina, triptofano, fenilalanina e isoleucina.

\section{Literatura Citada}

ARAÚJO, J.M.A. Química de alimentos: teoria e prática. 1.ed. Viçosa, MG: Universidade Federal de Viçosa, 1995. 355p.

CAMPOS, M.G. Avaliação da quebra técnica e da qualidade do milho a granel, em função da temperatura de secagem e do tempo de armazenamento. 2001. 103f. Tese (Doutorado em Engenharia Agrícola) - Universidade Federal de Viçosa, Viçosa, MG, 2001.

CARPENTER, K.J. Damage to lysine in food processing: its measurement and its significance. Nutrition Abstract \& Reviews, v.43, p.423-51, 1973.

COON, C.N. Optimizing ingredient utilization trhough a better understanding of aminoacid boivailability. In: TECHINICAL SYMPOSIA, 1991, Aruba. Proceedings... Aruba: Novus International, 1991. p.11-40.

COSTA, P.M.A.; JENSEN, A.H.; HARMON, B.G.E. et al. The effects of roasting and temperatures on the nutritive value of corn for swine. Journal of Animal Science, v.42, n.2, p.365-374,1976.

COSTA, P.M.A.; JENSEN, A.H.; HARMON, B.G. et al. Effects of roasting and roasting temperatures on the nutritive value of high-moisture corn for swine. Journal of Animal Science, v.44, n.2, p.234-241, 1977b.

DALE, N. Efeito da qualidade no valor nutritivo do milho. In: CONFERÊNCIA APINCO DE CIÊNCIA E TECNOLOGIA AVÍCOLAS, 1994, Campinas. Anais... Campinas: Fundação Apinco de Ciência e Tecnologia Avícolas, 1994. p.67-72.

FISHER JR., A.A.; ALBINO, L.F.T.; ROSTAGNO, H.S. et al. Determinação dos valores de energia metabolizável de alguns alimentos usados na alimentação de aves. Revista Brasileira de Zootecnia, v.27, n.2, p.314-318, 1998.

HATHAWAY, I.L.; YOUNG, F.D.; KIESSELBACH, T.A. The effect of drying temperature upon the nutritive value and commercial grade of corn. Journal of Animal Science, v.11, p.430, 1952.
JUSTICE, O.L.; BASS, L.N. How seeds are dried. In: Principles and praticies of seed storage. London: Caste House Publication, 1979. p.94-123.

MILLER, E.L.; HARTLEY, A.W.; THOMAS, D.C. Availability of sulphur amino acids in protein foods. Effect of heat treatament upon the total amino acid content of cod muscle. British Journal Nutrition, v.19, p.565-573, 1965.

MORAN JR., E.T.; SUMMERS, J.D. Factors in feed processing affecting utilization of nutrients. Feedstuffs, v.42, p.26, 1970.

NATIONAL RESEARCH COUNCIL - NRC. Nutrient requirements of poultry. 9.ed. Washington, D.C.: National Academy Press, 1994. 155p.

PUPA, J.M.R. Rações para frangos de corte formuladas com valores de aminoácidos digestíveis verdadeiros, determinados com galos cecectomizados. 1995. 63f. Dissertação (Mestrado em Zootecnia) - Universidade Federal de Viçosa, Viçosa, MG, 1995.

PUPA, J.M.R.; LEÃO, M.I.; CARVALHO, A.U. et al. Cecectomia em galos sob anestesia local e incisão abdominal. Arquivo Brasileiro de Medicina Veterinária e Zootecnia, v.50, n.5, p.531-535, 1998.

ROSTAGNO, H.S.; FEATHERSTON, W.R. Estudo de métodos de determinação de disponibilidade de aminoácidos em pintos. Revista da Sociedade Brasileira de Zootecnia, v.6, p.64-75, 1977.

ROSTAGNO, H.S. Disponibilidade de nutrientes em grãos de má qualidade. In: CONFERÊNCIA APINCO DE CIÊNCIA E TECNOLOGiA AVÍCOLAS, 1993, Campinas. Anais... Campinas: Fundação Apinco de Ciência e Tecnologia Avícolas, 1993. p.129-139.

ROSTAGNO, H.S.; NASCIMENTO, A.H.; ALBINO, L.F.T. Aminoácidos totais e digestíveis para aves. In: SIMPÓSIO INTERNACIONAL SOBRE NUTRIÇÃO DE AVES, 1999, Campinas. Anais... Campinas: Fundação Apinco de Ciência e Tecnologia Avícolas, 1999. p.65-83.

ROSTAGnO, H.S.; ALBINO, L.F.T.; DONZELE, J.L. Tabelas brasileiras para aves e suínos: composição de alimentos $\mathrm{e}$ exigências nutricionais. Viçosa, MG: Editora UFV, 2000. 141p.

SGARBIERI, V.C. Proteínas em alimentos protéicos. São Paulo: Varela, 1996. 121p.

SIBBALD, I.R. The effect of duration of the excreta collection period on the true metabolizable energy values of feedingstuffs with slow rates of passage. Poultry Science, v.58, p.896-899, 1979.

SIBBALD, I.R. A biossay for avaible amino acid and true metabolizable energy in feedstuffs. Poultry Science, v.58, p.668-673, 1979b.

SIBBALD, I.R. Metabolic plus endogenous energy and nitrogen losses of adult cockerels: the correction used in the biossay for true metabolizable energy. Poultry Science, v.60, p.805-811, 1981.

SIBBALD, I.R.; WOLYNETZ, M.S. Estimates of retained nitrogen used to correct estimates of bioavailable energy. Poultry Science, v.64, p.1506-1513,1985.

SILVA, D.J. Análise de alimentos: métodos químicos e biológicos. 2.ed. Viçosa, MG: Universidade Federal de Viçosa, 1990. 165p.

SULLIVAN, J.E.; OWENS, F.N.; SHOCKEY, B.J. Corn roasting temperature e nutrient availability. Journal of Animal Science, v.37, p.291, 1973 (abstr).

UNIVERSIDADE FEDERAL DE VIÇOSA - UFV. SAEG - Sistema de análises estatísticas e genéticas. Versão 8.0.Viçosa, MG: 1999. 59p. (Manual do usuário). 